\section{EMBRYRIDDLE Aeronautical University}

SCHOLARLY COMMONS

\section{International Journal of Aviation,} Aeronautics, and Aerospace

\title{
A cross-sectional investigation of the relationships education, certification, and experience have with knowledge, skills, and abilities among aviation professionals
}

\author{
Daryl Watkins \\ Embry-Riddle Aeronautical University - Worldwide, watkind4@erau.edu \\ Jason M. Newcomer \\ Embry-Riddle Aeronautical University - Worldwide, jason.newcomer@erau.edu \\ Matthew P. Earnhardt \\ Embry Riddle Aeronautical University, earnharm@erau.edu \\ James W. Marion \\ Embry-Riddle Aeronautical University - Worldwide, marionj@erau.edu \\ Rose A. Opengart \\ Embry-Riddle Aeronautical University - Worldwide, opengarr@erau.edu \\ Aaron M. Glassman \\ Embry-Riddle Aeronautical University, glassf10@erau.edu
}

Follow this and additional works at: https://commons.erau.edu/ijaaa

Part of the Management and Operations Commons, Other Education Commons, and the Training and Development Commons

\section{Scholarly Commons Citation}

Watkins, D., Newcomer, J. M., Earnhardt, M. P., Marion, J. W., Opengart, R. A., \& Glassman, A. M. (2016). A cross-sectional investigation of the relationships education, certification, and experience have with knowledge, skills, and abilities among aviation professionals. International Journal of Aviation, Aeronautics, and Aerospace, 3(1). https://doi.org/10.15394/ijaaa.2016.1101

This Article is brought to you for free and open access by the Journals at Scholarly Commons. It has been accepted for inclusion in International Journal of Aviation, Aeronautics, and Aerospace by an authorized administrator of Scholarly Commons. For more information, please contact commons@erau.edu. 
A cross-sectional investigation of the relationships education, certification, and experience have with knowledge, skills, and abilities among aviation professionals

\section{Cover Page Footnote}

We thank the many selfless aviation professionals who dedicated their time to taking the KCM to support the findings in this study. We also thank the editorial staff and reviewers of the IJAAA for their contributions to improving the quality of this study. 
The aviation industry is a complex system with many different segments and as such, makes hiring the right person a complicated endeavor (Loffi, Bliss, \& Depperschmidt, 2013). Hiring within the aviation industry is very competitive, and the stakes for failure are high. It is critical that positions be filled with applicants who closely match the job competencies (Sweem \& Stowe, 2012). Human resource and hiring managers must understand the competencies required for a particular job and be able to match people to positions. To assist in this process, human resource managers have identified knowledge, skills, and abilities (KSAs) as both selection and hiring criteria for jobs (Ashan, Ho, \& Khan, 2013; Sekiguichi \& Huber, 2011). Neistadt and Murphy (2009) noted that hiring individuals without the right mix of KSAs can cost an organization in multiple ways.

Earnhardt, Newcomer, Watkins, and Marion (2014) suggested that KSAs are composed of elements that include education, certification, and experience (ECE). It is important to understand how education, certification, and experience relate to KSAs. Formal aviation education programs date back to the early 1900s (Radigan, 2011). Aviation education programs are held in high regard by industry professionals and are important for upward mobility in the aviation field (Earnhardt et al., 2014; Fullingim, 2011). Likewise, certification plays a significant role in aviation, as many jobs require some form of certification (FAA, 2010). Certification is considered a critical link to safe operations in certain aviation career fields and is required for operating, maintaining, and servicing aircraft (Earnhardt et al., 2014; Sadasivan \& Gramopadhye, 2009). Experience is also seen as an important requirement in aviation fields. Consequently, commercial aviation has traditionally drawn heavily from the military forces because of the experience gained through military aviation fields (Ruiz, 2007).

\section{Problem Statement}

Newcomer, Marion, and Earnhardt (2014) conducted an aviation management education study (AMES) that focused on aviation managers' perspectives on postsecondary education within their organization. The study identified a paradigm shift in how aviation professionals perceived the importance of education to their career development. The foregoing fostered additional research into the aviation management education paradigm shift (Earnhardt et al., 2014). Earnhardt et al. theorized that the relative importance of ECE was dependent upon the aviation industry sector of the interviewees. As a result, the authors identified a logical connection between employees' ECEs and their KSAs. Shawn, Kim, and Jintendra (2014) asserted that KSAs are important because they influence hiring and retention decisions. Their findings support the need to understand better the relationship between KSAs and ECE in the aviation industry.

The relative importance of education, certification and experience is dependent on the type of job within the aviation sector (Earnhardt et al., 2014). To date, there has been no exploration of how ECE relates to KSAs (Earnhardt et al., 2014). The current study answers a call by Earnhardt et al. (2014) to explore the 
perceived relationships between aviation professional ECEs and the development of their KSAs. This mixed methods concurrent triangulation study explores the relationship between ECEs and KSAs using a sample of aviation industry professionals.

\section{Purpose Statement}

The objective of this mixed methods concurrent triangulation study was to examine aviation industry professionals' perceived relationship between ECEs and the development of their KSAs. The study made several significant contributions to the human resource management and aviation fields:

- A theoretical contribution is the operationalization of the KSA Composite Measure (KCM) created by Glassman, Newcomer, Earnhardt, Opengart, Watkins, and Marion (2015). The foregoing pilot study validated the instrument; however, this study is the initial deployment of the instrument for a large-scale study.

- A practical contribution of the study was that it provided empirical evidence for the theoretical framework developed by Earnhardt et al. (2014; see Figure 3). In doing so, the study clarified relationships between ECEs and KSAs that managers in the aviation industry can apply when developing job openings, conducting interviews, reviewing applicant credentials, and building high-performance teams. Additionally, the framework can be applied to fields other than aviation to illuminate similar relationships.

- Finally, the study contributed to aviation education industry practice by highlighting the importance of experience as it pertains to performance. With a large number of aviation programs requiring practical application of skills (e.g., pilot training, air traffic control training, meteorology, and engineering) it is important for universities to understand the ECE/KSA relationship when developing programs to meet industry needs.

\section{Conceptual Framework}

Identifying a research gap regarding aviation management education, Newcomer et al. (2014) proposed a framework for future aviation studies. The initial framework used a NASA style systems engineering work breakdown structure (WBS) that was employed by NASA (Earnhardt et al., 2014; Newcomer et al., 2014). Figure 1 shows the connection with the current study as indicated in the aforementioned WBS breakdown. 


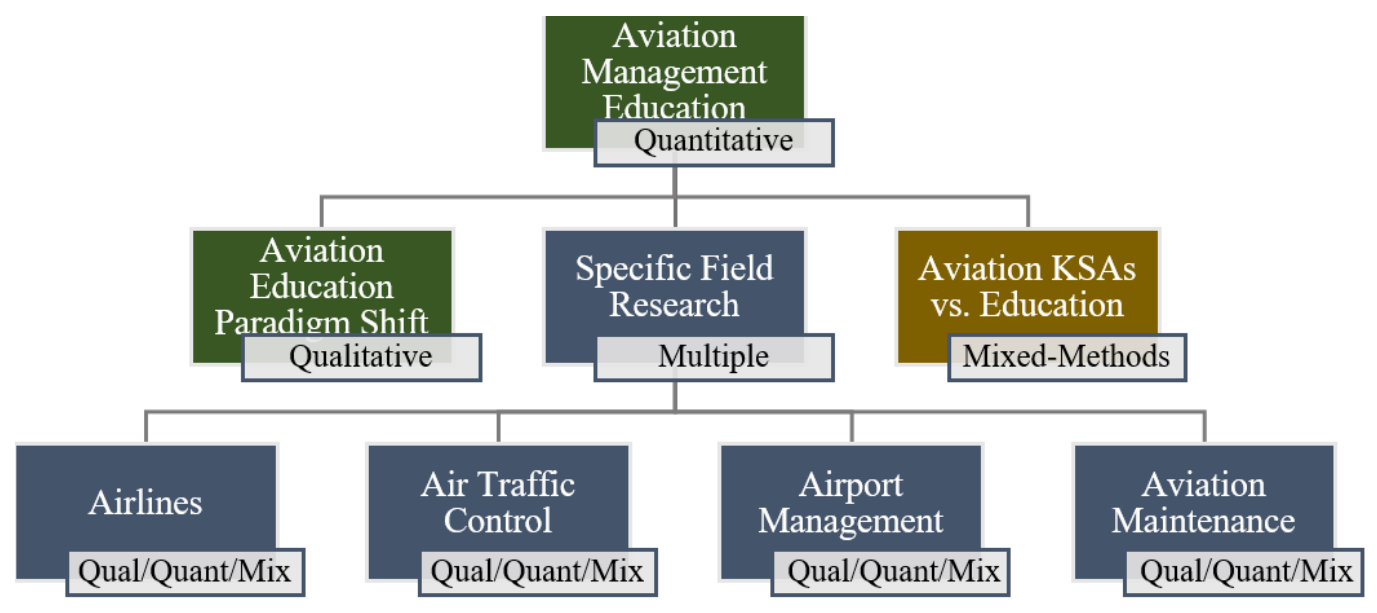

\section{Previous Current Literature Gap}

Figure 1. Previous, current, and future AMES initiatives required researching fully the aviation management education gap. Adapted from "Aviation Managers' Perspective on the Importance of Education" by J. M. Newcomer, J. W. Marion Jr, and M. P. Earnhardt, 2014, International Journal of Aviation, Aeronautics, and Aerospace. Reprinted with permission.

\section{Definitions}

The research team used the following definitions during the investigation:

Certification - Credentialed skills such as an Airframe and Powerplant (A\&P) license, pilot's license or similar credentials and ratings (Earnhardt et al., 2014).

Education - Academic knowledge gained from a post-secondary institution (Earnhardt et al., 2014).

Experience - Knowledge or wisdom one gains through exposure to a profession over time (Earnhardt et al., 2014).

KSAs - Knowledge, skills, and ability (or aptitude) are competencies required for a job (Stowe, Haefner and Behling, 2010).

Knowledge - A body of information needed to be proficient within a job (Flynn, 2014).

Skills - An aptitude obtained through effort to be proficient within a job (Flynn, 2014).

Abilities - The behaviors that are necessary to be proficient within a job (Flynn, 2014).

\section{Literature Review}

Earnhardt et al. (2014) identified a logical connection between employees' ECEs and their knowledge, skills, and abilities (KSAs) in a study of aviation managers. The findings of the aforementioned study indicated that ECEs are important but dependent on the particular aviation related job. Addressing a 
literature gap, the current mixed methods concurrent triangulation study sought to understand the ECE and KSA relationship in the aviation industry.

\section{Knowledge, Skills, and Abilities (KSAs)}

Research on employee selection has traditionally focused on the assessment of the match between job requirements and qualifications of job candidates in terms of their KSAs (Sekiguichi \& Huber, 2011). KSAs are general descriptions of minimum qualifying competencies, education, training, and abilities within a trade or career (Johnson, Lenartowicz, \& Apud, 2006). KSAs are an important aspect of job descriptions and hiring criteria in both the public sector and the private (HR in the Federal Sector, 2006). Employees currently occupying a position can assist in the identification of important KSAs for that position (Mathis, Jackson, \& Valentine, 2011). The match of an employee's KSAs has been used as a major hiring criterion for the past three decades (Kristof-Brown, 2000; Moy \& Lam, 2004). A mismatch occurs from incorrect coupling of a person's needs, interests, abilities, personality, and expectations with a job's characteristics, rewards, and the organization (Mathis et al., 2011). Recruiting the right person for the right job is a challenge for many human resource personnel and managers alike (Ashan, Ho, \& Khan, 2013). Managers are looking for the right mix of knowledge, skills, and abilities for the specific job opening and also seek to hire the right fit both from a job and organizational perspective (Sekiguichi \& Huber, 2011). Applicants who assess a job and conclude a high similarity between their KSAs and the job requirements are more likely to apply to, as well as accept, a job offer (Breaugh \& Starke, 2000; Carless, 2005).

KSAs in the $21^{\text {st }}$ century have focused on information, media, technology literacy, inventive thinking, communication, collaboration, productivity, and results. Unfortunately, many graduates fall short of having all of these required competencies (Boyles, 2012). Much of the global workforce lacks the KSAs and talent necessary for the modern workplace (Burke \& $\mathrm{Ng}$, 2006). The right KSAs are important for all types of workers, including executives, in for-profit, nonprofit, and government enterprises (Sweem \& Stowe, 2012).

Neistadt and Murphy (2009) noted that hiring individuals without the right mix of KSAs has significant organizational implications. Therefore, understanding what competencies are required for the job and how the employee matches those competencies is important. These KSAs are specific for the job; in other words, a pilot requires different KSAs from a navigator or an airframe mechanic. Furthermore, the KSAs required for a conventional pilot may be different from the KSAs required for flying an unmanned aircraft (Liu, Reynolds, Vincenzi \& Doherty, 2013).

The maximization of individual performance of the employee through improvement of KSAs is of supreme importance in organizations (Ascher, 2013). KSAs extend beyond just individual performance, however, as those KSAs needed 
to work successfully in a team may differ and are important for many types of work (Aguando, Arranz, Valera-Rubio \& Marin-Torres, 2011). Fraser and Hvolby (2010) indicated that over $80 \%$ of organizations with 100 or more employees use teams as part of their work.

\section{Aviation Education, Certification, and Experience}

There is a long history with aviation post-secondary education dating back to the early 1900s (Radigan, 2011). As aviation education matured from the early beginnings, the aviation accreditation body (AABI) set forth standards for aviation related academic programs at all post-secondary academic levels (AABI, 2014; Quilty, 2004). These programs feed the aviation industry with personnel. The primary focus of aviation in most aviation-related education programs is flight education (Earnhardt et al., 2014; Quilty, 2004). Quilty (2004) noted that though the AABI ensures foundational knowledge, students should have a broad variety of aviation education that broadens the understanding of systems and how different components function together. Furthermore, post-secondary education in aviationrelated programs is an important pathway to gaining aviation experience. Airline carriers hold aviation-related education programs in high regard (Fullingim, 2011). In certain career paths, education is required for upward mobility within the aviation industry (Earnhardt et al., 2014). Clark (2006) discussed a variety of reasons students choose an aviation-centric post-secondary program, with the most prevalent reason the desire to fly. Additional attractors for programs are education quality, university reputation, location, class size, program characteristics, studentto-faculty ratio, and other considerations. The findings by Clark (2006) indicate that aviation is a very influential motivator for enrolling in industry-specific education programs, and those students expect their chosen institution to provide a quality education that prepares them for the industry.

Certification is an important part of the aviation industry, as many aviationrelated jobs, airports, and even space operations, require certification (FAA, 2010). As discussed by O'Neil (2011), certifications provide a high degree of mission reliability because of the skills that are taught. The FAA ensures proper training and competency requirements are met among those that service, maintain, or operate aircraft (Kraus \& Gramopadhye, 2001; Sadasivan \& Gramopadhye, 2009). One example is the certification process of air traffic controllers, which requires written examinations, on-the-job training, and performance measures (Earnhardt et al., 2014). Air traffic controllers undergo intense initial and follow-on training, which provides operational air traffic controllers with the technical skills to meet the demands of emergency situations (Malakis \& Kontogianis, 2012). The reason for such robust training is that the ATC is a critical safety system with training taking place in several phases and devoted to technical skills (Malakis \& Kontogianis, 2012). In addition to training, in order to operate as an air traffic controller one must possess a valid air traffic control specialist certificate or a control tower operator certificate which demonstrates knowledge in meteorology, air navigation, communication, navigation aids, and regulations governing air 
traffic (OPM.gov, n.d.). Other certifications such as A\&P license, pilot license, air transport pilot, and others require similar rigor and requirements to be certified to operate, maintain, or service aircraft (Earnhardt et al., 2014; Sadasivan \& Gramopadhye, 2009).

As noted by Earnhardt et al. (2014), experience is the most important hiring requirement in the aviation industry. Traditional hiring practices in aviation centered on recruiting individuals from the military with prior experience (Ruiz, 2007). This important hiring pool allowed aviation hiring managers to hire from an experienced workforce. Experience is important in judging performance among pilots (Roth \& Mavin, 2015). As such, experience is seen as one of the biggest obstacles new pilots face in gaining the appropriate experience that commercial operators desire (Ruiz, Voges \& Mortag, 2006). Given the context of the above, the following research questions were developed to understand the relationship between aviation industry professionals ECEs, and how that relates to their KSAs.

\section{Research Question}

Three central research questions guided the study:

1. Is there a significant difference between the Education, Certification, and Experience KSA ratings? Why or why not?

2. Is there a relationship between KSA factors and the importance to the job? Why or why not?

3. Does having a certification change the importance of how an individual views education and experience KSAs? Why or why not?

\section{Hypotheses}

\section{Hypothesis 1: Difference between ECE KSA Ratings}

- H10: There is no significant difference between the importance of Education, Certification, and Experience as they pertain to KSAs.

- $\mathrm{H} 1_{\mathrm{a}}$ : Experience will be the most important KSA factor.

- H1b: Certification will be the most important KSA factor.

- $\mathrm{H} 1_{\mathrm{c}}$ : Education will be the most important KSA factor.

\section{Hypothesis 2: KSA Impact vs. Job Importance}

- $\mathrm{H} 2_{0}$ : There will be no relationship between factors rating for personal KSA impact and the importance of those factors to the job.

- $\mathrm{H} 2_{\mathrm{a}}$ : Factors that were important to personal KSA development are also important to the job for which that person was hired.

\section{Hypothesis 3: Certified vs. Uncertified}


- $\mathrm{H} 3_{0}$ : There is no difference in Education and Experience impact based on certification status.

- H3a: Education and experience are less important to those who possess a certification in their particular field.

\section{Methodology}

We conducted a mixed methods concurrent triangulation study to understand the relationship between aviation industry professionals ECEs and their KSAs required in their aviation careers. The concurrent triangulation design was most appropriate for the research in order to examine the relationship(s) between/among variables while simultaneously gleaning a depth of scholarship regarding the meaning of those relationships from direct participant feedback (Creswell, 2009). Additionally, the method/design combination contributed best to generating concrete, generalizable findings for the aviation industry.

\section{Population and Sampling}

The convenience sample consisted of professionals who work or have worked in the aviation industry $(n=404)$. Participants were recruited over a fourweek period via LinkedIn ${ }^{\mathrm{TM}}$ advertising within various aviation-focused professional groups. A priori power analysis $(w=0.25, p=0.05,1-\beta>0.95$, Df $=8$ ) using $\mathrm{G}^{*}$ Power 3.1.9.2 indicated a sample size of 378 to achieve a power of .80). The sample size $(n=404)$ supports the findings with a $95 \%$ confidence level and a $4.87 \%$ confidence interval for the population $(N>200,000)$.

Table 1

Sample Occupation Demographics

\begin{tabular}{lcc}
\hline \multicolumn{1}{c}{ Occupation } & $f$ & Percent \\
\hline Air Traffic Control & 52 & 12.9 \\
Aircraft Maintenance & 85 & 21.0 \\
Aircraft or Aircraft Systems & 60 & 14.9 \\
Manufacturing and Design & 80 & 19.8 \\
Airlines/Pilot (Civilian or Military) & 32 & 7.9 \\
Airports Operations & 19 & 4.7 \\
Aviation Education & 9 & 2.2 \\
Aviation Logistics & 12 & 3.0 \\
Aviation Support Services (e.g., fuels, & 55 & 13.6 \\
security, etc.) & 404 & 100.0 \\
Other Aviation Occupation & & \\
Total & &
\end{tabular}

This convenience sample allowed a rapid cross-section of multiple aviation sectors to be reached with a single advertisement so that a diverse group of participants could be surveyed. Although not as generalizable as a random sample, 
the ease of access to a diverse group of aviation professionals from different sectors as well as the large number of responses $(n=404)$ outweigh any potential limitations of the sampling method. Table 1 depicts the occupational demographics of the population which are representative of sectors within the aviation industry.

\section{Validity and Reliability}

We used the Knowledge, Skills, and Abilities (KSA) Composite Measure $(\mathrm{KCM})$ as the data collection device for the study. The KCM contained Likert-type closed-ended questions for quantitative analysis and open-ended short answer questions for qualitative analysis. Glassman et al. (2015) conducted a pilot study consisting of (a) a panel of experts, (b) an ethics review, and (c) a factor analysis and reliability test to confirm the validity and reliability of the KCM. Table 2 displays the specific data reliability for the current sample population $(n=404)$. The general guidelines for alpha values: 0.90 to 1.0 are excellent, 0.80 to 0.89 are good, 0.70 to 0.79 are acceptable, 0.60 to 0.69 are questionable, 0.50 to 0.59 are poor, and below .50 are unacceptable (George \& Mallery, 2003).

Table 2

Cronbach's a by Factor

\begin{tabular}{lcc}
\hline Factor & Cronbach's $\alpha$ & Rating \\
\hline Education & 0.87 & Good \\
Certification & 0.90 & Excellent \\
Experience & 0.82 & Good \\
\hline
\end{tabular}

\section{Results}

\section{Quantitative Analysis}

Hypothesis 1: Difference between ECE KSA Ratings. Survey respondents were asked to rank the importance of Education, Certification, and Experience in terms of its contribution to Knowledge, Skills, and Abilities. The data was collected using a Likert-type scale with selections ranging from "Very important" to "Of little importance." The responses were coded from 1-4 and the responses were tabulated.

The ANOVA was selected as a test for significant differences between the nine different response categories. The ANOVA is traditionally applied in cases of ratio or interval data and Likert data is considered to be ordinal. However, empirical tests demonstrate that parametric tests such as the ANOVA and the t-tests are appropriate for use in the analysis of ordinal Likert data (Carifio \& Perla, 2008; de Winter \& Dodou, 2010). Further, using such parametric tests have the potential to produce stronger analyses and highlight results from data that non-parametric analysis might miss (Norman, 2010). The $F$ test has been demonstrated to produce accurate results when Likert ordinal data are treated as interval data in analysis (Carifio \& Perla, 2007). The ANOVA data, $F(8,3027)=1.94, p=.001$, 
demonstrated a significant difference between the KSA groups with a $p$ value approximating zero (see Tables 3 and 4).

Table 3

ANOVA test for significant differences between KSA groups

\begin{tabular}{lrrrrrrrr} 
& \multicolumn{1}{c}{ Alpha } & 0.05 \\
\hline EdK & 404 & 1290 & 3.19 & 0.90 & 360.94 & 0.05 & 3.10 & 3.28 \\
EdS & 404 & 1149 & 2.84 & 1.15 & 463.18 & 0.05 & 2.75 & 2.94 \\
EdA & 404 & 1148 & 2.84 & 1.11 & 445.86 & 0.05 & 2.75 & 2.93 \\
CeK & 204 & 612 & 3.00 & 1.23 & 250.00 & 0.07 & 2.87 & 3.13 \\
CeS & 204 & 589 & 2.89 & 1.36 & 276.40 & 0.07 & 2.76 & 3.02 \\
CeA & 204 & 545 & 2.67 & 1.50 & 305.00 & 0.07 & 2.54 & 2.80 \\
ExK & 404 & 1474 & 3.65 & 0.40 & 162.09 & 0.05 & 3.56 & 3.74 \\
ExS & 404 & 1479 & 3.66 & 0.40 & 160.54 & 0.05 & 3.57 & 3.75 \\
ExA & 404 & 1461 & 3.62 & 0.52 & 209.53 & 0.05 & 3.53 & 3.71
\end{tabular}

Table 4

Sources of Variation for KCM Factors

\begin{tabular}{lrrrrc}
\hline \multicolumn{1}{c}{ Sources } & \multicolumn{1}{c}{ SS } & df & \multicolumn{1}{c}{ MS } & \multicolumn{1}{c}{$F$} & \multicolumn{1}{c}{$p$} \\
\hline Between Groups & 424.96 & 8 & 53.12 & 61.06 & $<.001$ \\
Within Groups & 2633.54 & 3027 & 0.87 & & \\
Total & 3058.51 & 3035 & 1.00 & & \\
\hline
\end{tabular}

What specific differences were observed between the groups? From inspection of the data, the top three highest mean Likert scores were observed for Experience and Skills, Experience and Knowledge, and Experience and Abilities. In contrast, the bottom three scores included Education and Skills, Education and Abilities, and finally, Certification and Abilities (see Table 5).

Table 5

Means sorted for inspection and Tukey test

\begin{tabular}{cc}
\hline Group & Mean \\
\hline ExS & 3.66 \\
ExK & 3.65 \\
ExA & 3.62 \\
EdK & 3.20 \\
CeK & 3.00 \\
CeS & 2.89 \\
EdS & 2.84 \\
EdA & 2.84 \\
CeA & 2.672 \\
\hline
\end{tabular}


Further, a Tukey post-hoc test was conducted to determine which groups exhibited differences that were statistically significant and therefore contributed to the overall ANOVA results (see Table 6). The post-hoc test revealed a number of groups that exhibited differences that were statistically significant.

Table 6

Multiple comparison post-hoc Tukey test for significant differences between KSA groups

\begin{tabular}{ccccccc}
\hline Group 1 & Group 2 & Delta means & SE & \multicolumn{1}{c}{$q$} & \multicolumn{1}{c}{$p$} & Significant? \\
\hline ExS & CeA & 0.99 & 0.06 & 17.46 & $<.001$ & Yes \\
ExS & EdA & 0.82 & 0.05 & 17.66 & $<.001$ & Yes \\
ExS & EdS & 0.82 & 0.05 & 17.60 & $<.001$ & Yes \\
ExS & CeS & 0.77 & 0.06 & 13.66 & $<.001$ & Yes \\
ExS & CeK & 0.66 & 0.06 & 11.67 & $<.001$ & Yes \\
ExS & EdK & 0.47 & 0.05 & 10.08 & $<.001$ & Yes \\
ExK & CeA & 0.98 & 0.06 & 17.25 & $<.001$ & Yes \\
ExK & EdA & 0.81 & 0.05 & 17.39 & $<.001$ & Yes \\
ExK & EdS & 0.80 & 0.05 & 17.34 & $<.001$ & Yes \\
ExK & CeS & 0.76 & 0.06 & 13.44 & $<.001$ & Yes \\
ExK & CeK & 0.65 & 0.06 & 11.45 & $<.001$ & Yes \\
ExK & EdK & 0.46 & 0.05 & 9.81 & $<.001$ & Yes \\
ExA & CeA & 0.95 & 0.06 & 16.68 & $<.001$ & Yes \\
ExA & EdA & 0.78 & 0.05 & 16.70 & $<.001$ & Yes \\
ExA & EdS & 0.77 & 0.05 & 16.64 & $<.001$ & Yes \\
ExA & CeS & 0.73 & 0.06 & 12.87 & $<.001$ & Yes \\
ExA & CeK & 0.62 & 0.06 & 10.88 & $<.001$ & Yes \\
ExA & EdK & 0.42 & 0.05 & 9.12 & $<.001$ & Yes \\
EdK & CeA & 0.52 & 0.06 & 9.21 & $<.001$ & Yes \\
EdK & EdA & 0.35 & 0.05 & 7.57 & $<.001$ & Yes \\
EdK & EdS & 0.35 & 0.05 & 7.52 & $<.001$ & Yes \\
EdK & CeS & 0.31 & 0.06 & 5.40 & $<.001$ & Yes \\
CeK & CeA & 0.33 & 0.05 & 7.08 & $<.001$ & Yes \\
\hline
\end{tabular}

The number of significant differences observed in the post-hoc test suggests that the differences between the groups observed by inspection are in fact significant and that multiple groups contribute to the ANOVA findings.

Hypothesis 2: KSA Impact vs. Job Importance. The KSA scoring questions asked respondents to rate the importance of Education, Certification, and Experience as it relates to Knowledge, Skills, and Abilities. Respondents were 
further asked to rank the importance of Education, Certification, and Experience to their job. It is of interest to consider those who ranked Education, Certification, and Experience highly throughout all KSAs also ranked the factor highest in importance with respect to their current employment.

Education. The first factor considered was Education. Respondents who scored Education highly across all KSAs also ranked Education highly in terms of importance to their employment (see Table 7). Out of 101 respondents who scored Education as "Very important" across all KSAs, 53.47\% also ranked Education as highest importance to employment requirements.

Table 7

Ranking of ECEs among those who scored education highly

\begin{tabular}{llll}
\hline Category & Rank 1 & Rank 2 & Rank 3 \\
\hline Education & $54(53.47 \%)$ & $34(33.66 \%)$ & $13(12.87 \%)$ \\
Certification & $7(6.93 \%)$ & $25(24.75 \%)$ & $69(68.32 \%)$ \\
Experience & $40(39.60 \%)$ & $42(41.58 \%)$ & $19(18.81 \%)$ \\
Total & 101 & 101 & 101 \\
\hline
\end{tabular}

Certification. The second factor considered was Certification. Respondents who scored Certification highly across all KSAs ranked Experience rather than Certification highly in terms of importance to their employment (see Table 8). Out of 55 respondents who scored Certification as "Very important" across all KSAs, $43.64 \%$ ranked Experience as highest importance to employment requirements.

Table 8

Ranking of ECEs among those who scored certification highly

\begin{tabular}{llll}
\hline Category & Rank 1 & Rank 2 & Rank 3 \\
\hline Education & $18(32.73 \%)$ & $10(18.18 \%)$ & $27(49.09 \%)$ \\
Certification & $13(23.64 \%)$ & $26(47.27 \%)$ & $16(29.09 \%)$ \\
Experience & $24(43.64 \%)$ & $19(34.55 \%)$ & $12(21.82 \%)$ \\
Total & 55 & 55 & 55 \\
\hline
\end{tabular}

Experience. The third factor considered was Experience. Respondents who scored Experience highly across all KSAs also ranked Experience highly in terms of importance to their employment (see Table 9). Out of 245 respondents who scored Experience as "Very important" across all KSAs, 66.53\% ranked Experience as highest importance to employment requirements. 
Table 9

Ranking of ECEs among those who scored experience highly

\begin{tabular}{llll}
\hline Category & Rank 1 & Rank 2 & Rank 3 \\
\hline Education & $59(24.08 \%)$ & $93(37.96 \%)$ & $93(37.96 \%)$ \\
Certification & $23(9.39 \%)$ & $92(37.55 \%)$ & $130(53.06 \%)$ \\
Experience & $163(66.53 \%)$ & $60(24.49 \%)$ & $22(8.98 \%)$ \\
Total & 245 & 245 & 245 \\
\hline
\end{tabular}

Hypothesis 3: Certified vs. Uncertified. Approximately half of all survey respondents reported that they held certifications. Given the divided respondent population, it is of interest to determine if any significant difference in how respondents with and without certifications rated Education and Experience importance across the KSA. An independent sample $t$-test was performed for both Education and Experience scores for respondents with and without certifications. Unequal variances are assumed given that the population of certified versus uncertified respondents were different.

Education. No significant difference was observed between how certified $(M=8.73, \quad S D=2.89, \quad N=204)$ and uncertified $(M=9.03, \quad S D=2.55, \quad N=200)$ respondents ranked education $t(397)=-1.10, p=.27$, two tailed.

Experience. The $t$-test for significant difference in Experience scores between those with $(M=11.08, S D=1.57, N=204)$ and without $(M=10.78, S D=1.83$, $N=200)$ certifications was performed. The two-tailed test suggested no significant difference $t(390)=1.77, p=.08$. However, the one-tailed test was informative. The one-tailed test was performed to determine if Experience KSA scores were significantly higher for those who held certifications. The result of the one-tailed test $t(390)=1.77, p=.04$ suggests that those with certifications scored Experience KSAs higher than those without certifications.

We observed that there is a significant difference between the ECE KSA scores at the .05 level of significance. Experience and Skills, Experience and Abilities, and Education and Knowledge appear in the top three category scores. The comparison of KSA scores and the ranking of Education, Certification, and Experience in terms of importance to the job illustrates that Certification is observed to follow a different pattern. The majority of respondents who scored Certification highly across the KSAs failed to rank Certification highest in terms of importance to the job. Instead, the majority of those who scored Certification highest ranked Experience as most important to the job. The $t$-test is consistent with the KSA scoring versus ranking analysis. The one-tailed $t$-test indicates a significant difference in that those with certifications scored experience more highly.

\section{Qualitative Analysis}

The open-ended survey responses were analyzed using nVivo 10. Themes 
in the survey comments were identified (see Table 10).

Table 10

Survey themes for experience, education, and certification variables.

Percent

$(n=304) \quad$ Theme

$32 \quad$ Experience is the practical part

22.5 Experience is additive

22.5 Education serves as a foundation, upon which experience builds

13 Certification maintains standards

10 Certification serves as validation

In addition, comments associated with education taken from respondents both with, as well as without, certification were noted. In order to understand the underlying meaning associated with each theme and to determine to what extent the qualitative data added context to the quantitative analysis, survey comment excerpts were extracted from each theme for compilation and discussion.

Theme \#1: Experience is the practical part. Survey respondents emphasized the limitations of formal education. The concern expressed was that its focus was centered upon theoretical knowledge that was of limited usefulness on the job. Because of this, formal education tended to be valued less than practical experience. Theme \#1 excerpts are provided as follows:

- "Book knowledge is only helpful to a point - experience and practice"

- "Experience is practical knowledge. Education is theoretical and of lesser value"

Theme \#2: Experience is additive. Survey respondents indicate experience is an essential ingredient that adds to formal education and activates it so that it becomes useful and actionable. Theme \#2 excerpts are provided as follows:

- "Experience adds to book knowledge and puts it in context"

- "Without actual experience in a real time environment, all the education one has is worthless. Experience allows the individual to develop the necessary skills."

Theme \#3: Education as a foundation, upon which experience builds. Survey respondents indicate that formal education is viewed as a starting point only. It is acknowledged that experience builds upon the foundation of formally obtained knowledge. Although the foundation is necessary, it is incomplete and only a foundation. Theme \#3 excerpts are provided as follows:

- "Education helped to develop a foundation for increased responsibility while providing a means to improve my capabilities and understanding of 
human relations and its effect on the business model."

- "Education forms a base of knowledge and basic skills from which to build. Abilities come with experience."

It was further noted in the survey comments that experience was considered to be of high importance even from those respondents who did not hold certifications. For example:

- "33+ years of career experience trumps education"

- "It is because you learn most after engaging to work, but education carved the basic skills to overcome"

Survey respondents who did hold certifications expressed a more negative view of education even to the extent of questioning its relevance. For example:

- "I am assuming by certification you are referring to licensing. You need knowledge to get the license, unfortunately much of the course has no relevance to the actual job. Skills are taught after licensing."

- "Certification is a necessary part of the job experience but actual experience is needed to fulfill the job."

Theme \#4: Standards. Survey respondents holding certifications identified the need to demonstrate standards of competence as well as knowledge of regulations. It was further emphasized that the aviation industry has a heightened concern for competence in industry standard skills. For example:

- "Certification requires an understanding of what the regulations and standards are for completing a task."

- "Aviation Business Certifications are very important, since they tell the world that you have reached a certain level of competency and that is recognized across a broad span of cultures/businesses."

Theme \#5: Validation. Survey respondents holding certifications sought certifications in order to recognize their knowledge as well as capabilities. Certifications therefore validate the know-how of the individual regardless of how it (unclear - the certification or the know-how?) was acquired. As expressed in the survey comments:

- "I think Certification allows to people to have a kind of Official recognition... of the professional level and knowledge capabilities."

- "Certification is a proof that one has acquired the right knowledge"

\section{Summary of qualitative findings.}

1. Education was observed to be important but only serves as a foundation upon which the experience will build. While education is not seen as helpful 
as experience, it is considered by the survey respondents to be a necessary foundational background. This foundation is considered essential in order to understand, integrate, and apply the experience gained after education.

2. Certification provides validation to both individual and the outside world that the person holds the necessary KSAs (Knowledge, Skills, and Abilities).

3. Certification ensures a minimum level of standard KSAs (Knowledge, Skills, and Abilities). It also validates (see above) that these standards have been reached.

4. Experience was observed to be additive. While most respondents identified experience as most important, and where "the real learning" occurs, it also adds to the foundation built by the education. In other words, it enabled the survey respondents to practically apply what they learned in the classroom.

\section{Discussion}

It is apparent that the quantitative and qualitative findings taken together identify a clear response pattern from the survey. The quantitative data illustrate that respondents ranked highly experience and skills, experience and abilities, and education and knowledge. The difference between the KSA scoring was found to be significant in the ANOVA. Further, experience was observed to score more highly than all KSA categories. Respondents with certifications also ranked experience highest in importance to current or previous employment. Finally, respondents holding certifications rated experience KSAs higher than education as compared to those who did not hold certifications.

The centrality of experience - as it relates to KSAs - is bolstered by the findings from the open-ended survey questions. While education provides a foundation, experience is observed to be essential for performance. Finally, certification serves to validate the KSAs that have been developed by experience and built upon the foundation of education. The combined findings of the quantitative and qualitative results are organized into the following conceptual framework in figure 2 . 


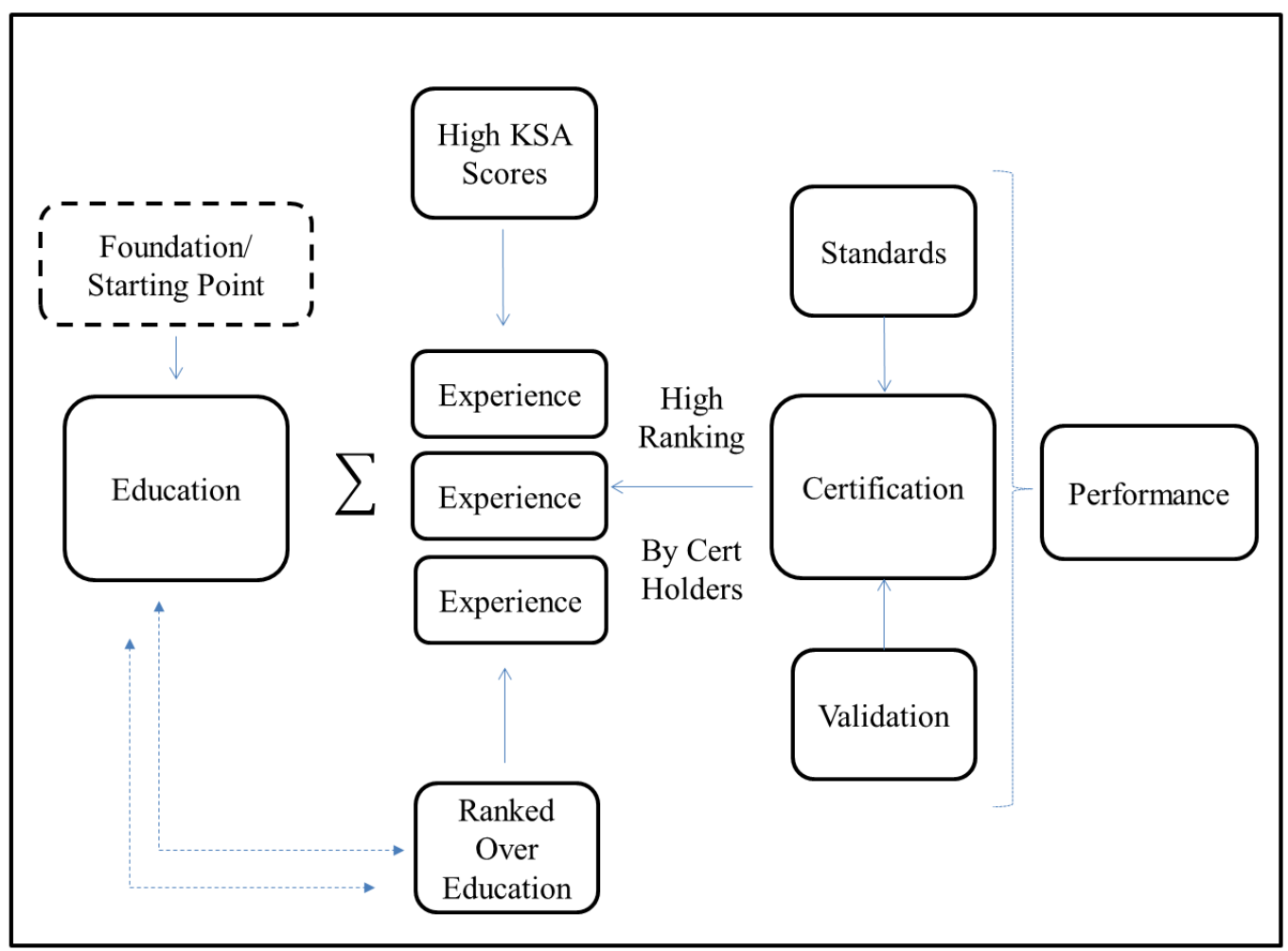

Figure 2. Emergent conceptual framework for ECE and KSA variables.

\section{Applications}

\section{Theoretical}

The current study validated the theoretical framework developed by Earnhardt et al. (2015; see figure 3). Education, certification, and experience were perceived to be building blocks for knowledge, skills, and abilities. It was beyond the scope of the study to determine the strength of the individual relationships. Education was perceived to be most important for developing knowledge and roughly equal for developing skill and ability. Certification was perceived to be somewhat important for developing knowledge, then skill, followed by ability. Experience was perceived to be most important for developing skill, then knowledge, then ability. Relative to each other, experience was perceived to be most important, then education, followed by certification in terms of the perceived impact on respondents KSAs. 


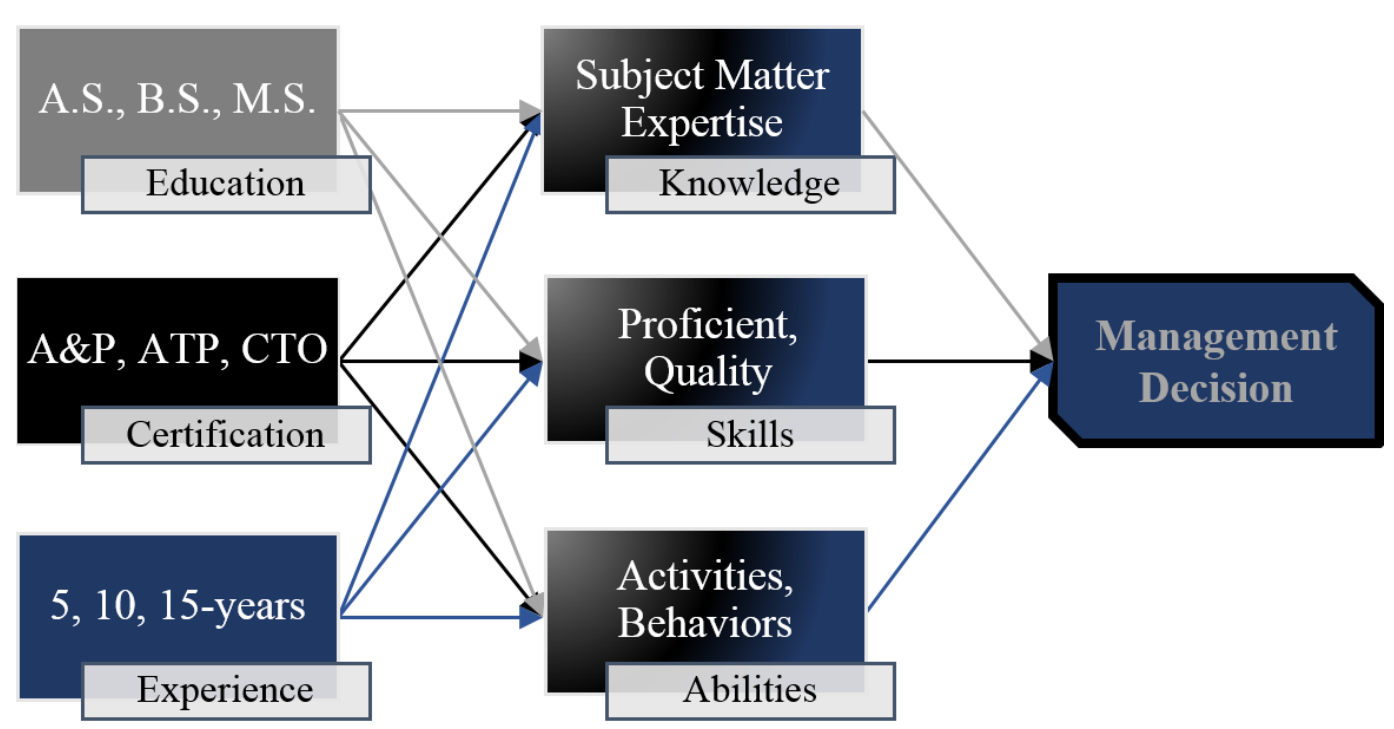

Figure 3. Theoretical framework linking education, certification, and experience to KSAs and the management decision to hire or select a team. Adapted from "An inquiry into the aviation management education paradigm shift" by M. P. Earnhardt, J. M. Newcomer, D. V. Watkins and J. W. Marion 2014, International Journal of Aviation, Aeronautics, and Aerospace. Reprinted with permission.

Human resources and training and development focus on competencies related to the KSAs. This focus applies to theoretical applications as well as management decisions like hiring (Wooten, 1993) and team selection (O'Neil, Goffin, \& Gellatly, 2012). ECEs serve as the building blocks for achieving those competencies. KSA models and theory could be updated to include the ECE concepts. For example, conflict resolution is considered an interpersonal KSA related to overall teamwork KSAs. Conflict resolution can be learned in a degree program, one can achieve certification in conflict resolution techniques, and one can obtain direct experience in conflict resolution. Existing models do not reflect this level of nuance.

\section{Practical}

There are several practical applications that can be drawn from the results of the study. First, the findings validate that experience is essential for performance. This has implications for aviation-centric post-secondary programs that prepare students for a career in the aviation field. These programs need to find a way to incorporate experience into their programs. Worrells (2010) indicated that the percentage of students in aviation management programs who participated in workbased learning during their academic career was $1.8 \%$. The findings of the current study would indicate that the importance of experience is critical to aviation jobs. There is an opportunity to bring more experiential learning into academic programs at the post-secondary level that would meet industry needs. This could be done through Worrells' recommendation of work-based learning opportunities, or through other experiential learning opportunities in post-secondary institutions. By 
doing so, post-secondary programs would be meeting industry needs and better differentiating themselves from other aviation-centric programs.

Second, education is found to be foundational, and experience is seen as an additive, which enables learners to apply practically what they have learned. This has implications for supervisors, training managers, and human resource professionals. As post-secondary education is seen as foundational, training programs may revise on-site to emphasize practical skills as opposed to theoretical concepts. In other words, students gain valuable theoretical knowledge in the classroom, which may make the need to emphasize such theoretical concepts unnecessary when developing training programs in the field. This could shorten the required training pipeline or could allow more time to emphasize hands-on experience during onboarding into aviation organizations. Furthermore, managers who typically use training time to cover in-depth theoretical concepts may find that just a brief overview is necessary and more time can be devoted to training other topics or providing hands-on experiences.

Finally, the importance of a certification cannot be overlooked. In certain career fields where certification is required, the results indicated that certification validates that an aviation professional has the minimum knowledge, skills, and abilities to perform in a certain job. For both aviation professionals and hiring managers, in those industries where certifications are required, this information is extremely important. For aviation professionals, it shows the importance of pursuing certifications to show a competence within a certain career field. One cannot underestimate the importance of showing competence on a resume prior to seeking employment. Training managers can use certifications, in jobs that require certifications, to develop a comprehensive training program and improve the KSAs of their employees. Additionally, it was clear that people with certifications valued their KSAs more than people who did not hold certifications. This is perhaps indicative that the process of gaining a certification provides a psychological boost, in effect proving to the certificate holder that their KSAs held more value. Confidence in one's KSAs might lead to improved performance and to higher regard from peers and supervisors.

\section{Assumptions and Limitations}

\section{Assumptions}

There are several important assumptions that exist within the context of this research. The first assumption is that the labels of education, certification, and experience are discrete bins with no overlap or underlap that could lead to confusion. For example, the classroom portion of flight school (e.g., learning meteorology) would not fit neatly into education, certification, or experience as defined here. But, the culmination of flight school is an FAA certificate so likely respondents would identify flight school training with certification or experience. While this could cause some confusion, it is assumed that most in the aviation 
industry would likely understand the nature of these distinctions and identify the relationship between knowledge, skills, and abilities and education, certification, and experience properly as it relates to their unique individual profile, job description and employer.

The second assumption is one of present vs. past recall. Respondents to this survey had, on average, 19 years of experience in their current or previous aviation job ( $\min =0$ years and $\max =63$ years). The presumption here is that those with 19 years of experience are speaking on behalf of today's industry conditions, not the conditions to which they were hired (circa 1996 or 19 years prior to the data of survey administration). Survey questions were worded in such a way to focus respondents on present industry conditions or their specific job description in aviation, and therefore it is assumed that responses reflect that focus.

The final assumption is one of sample diversity. Due to the nature of LinkedIn, it was impossible to target a specific population comprehensively. But, online advertisements and postings to dozens of aviation-related LinkedIn Groups funneled respondents to the online survey. There is some evidence in the literature that the use of special interest social media groups actually enhances the quality of responses since respondents are pre-screened based on interest (Patino, Pitta, \& Quinones, 2012). It is assumed that this sample represents the aviation industry at large and therefore can be generalized to all of the aviation industry. This assumption is loosely confirmed by the proportional representation from each aviation sector along with 56 respondents who chose "other" when asked what aviation sector in which they currently or most recently worked.

\section{Limitations}

The limitations associated with a convenience sample exist within this research although attempts to mitigate these effects were utilized. Only those who have a LinkedIn profile and access to the internet survey were able to participate. No paper surveys were used due to funding and time limitations. The opinions of those who do not participate in social media or have internet access were excluded, and therefore a non-response bias may exist (Sax, Gilmartin, \& Bryant, 2003). A social desirability bias may also exist since many online profiles contain fictitious or embellished information, and users were solicited to participate from social media. Guillory and Hancock (2012) found that frequency of deception in LinkedIn profiles is no more than on traditional resumes, and there is no known research on how recruiting via social media affects response accuracy or bias in internet surveys. Although some social desirability bias may be present (e.g., reporting of salary), many questions likely have no socially desirable answer, and an anonymous online survey poses the lowest likelihood of such bias (Kreuter, Presser, \& Tourangeau, 2008). While some forms of bias may be present, the design of the study has attempted to minimize those effects. 
The aviation industry is in the midst of a paradigm shift (Earnhardt et al., 2014) and where respondents view themselves within this shift is a limitation of this study. For example, the airline industry has changed its hiring practices for pilots to where total flight time is less important than other factors (e.g., college education). In addition, the military is producing fewer pilots than ever before, so pilot recruitment pipelines are shifting. Therefore, the results of the relationship between education, certification, and experience as it relates to knowledge, skills and abilities may be affected by where each respondent is within his or her career (e.g., early, mid, late) and where each specific career path and employer is within this paradigm shift. In addition, the sampling method (i.e., professional social media) may have skewed the results towards so-called "white collar" aviation roles (e.g., maintenance management) and may represent certain viewpoints more frequently than others. It is not known what effect this has on the data and anecdotally it could be said that the results are more likely to represent the preparadigm phase (Kuhn, 1996) where there may not be agreement per individual and per employer as to the best relationship of ECE to KSA. Future studies using the composite measure (longitudinal) would be needed to identify precisely where the aviation industry is as it relates to the paradigm shift identified by Earnhardt et al. (2014) and what affect it had on the survey responses.

\section{Recommendations}

There are several recommendations from the current study. First, the current study did not address the strength of individual relationships but did address the perceptions of individuals being hired. Since managers make hiring decisions based on KSAs, it would be instructive to determine the specific antecedents of KSAs and to determine their relative importance to KSA development. In other words, modeling the predictor variables for KSAs could provide managers with a more complete view of potential success criteria for new employees. Education, certification, and experience may predict a significant portion of KSAs, but there are likely other variables. Additionally, KSA predictors may vary dramatically by industry and sector. Further research should attempt to account for KSA predictors in different organizational contexts. The study used the Knowledge, Skills, and Abilities (KSA) Composite Measure (KCM) as the data collection device for the study. This instrument should be tested in future studies to confirm the validity and reliability of the instrument.

The study highlighted a need for post-secondary institutions to inject experiential learning into their aviation degree programs. Future research can determine if individuals who had experiential learning in their degree programs (as compared with those who did not have experiential learning) were able to capitalize on that experiential learning through additional career opportunities, promotions, or better performance.

Finally, certificate holders rated their KSAs higher than non-certificate holders. Certificate holders and non-certificate holders who do the same work 
should be studied to determine the performance and psychological effects of gaining a certificate.

\section{Conclusion}

Hiring managers talk about the importance of KSAs for their new hires. Job descriptions are developed around KSAs. Considerable research has been conducted around KSAs. The study demonstrated strong perceptual relations between ECEs and KSAs and opens the door for a new line of inquiry regarding the importance of ECEs to human resource management. Education forms a foundation for KSAs. Experience builds upon that foundation and is the essential ingredient of KSAs. Certification is perceived as a validator and further contributor to the KSAs.

The implications of the research findings suggest that more research is necessary to understand specific relationships between ECEs and KSAs. Industry specific models could be build that would help human resource professional improve hiring, job design, training, and performance management. Finally, from a practical perspective, educators need to find more ways to bring hands-on, experiential learning into the classroom. 


\section{Author Biographies}

Dr. Daryl Watkins is an Assistant Professor of Leadership with Embry-Riddle Aeronautical University-Worldwide. He holds a Doctorate of Management (DM) in Organizational Leadership and an MBA in Information Technology Management. He is a Microsoft Certified Systems Engineer (MCSE) and a Project Management Institute certified Project Management Professional (PMP).

Dr. (Major) Jason Newcomer, U.S. Air Force, is the Deputy Director for Air Traffic Control and Landing Systems Logistics and Maintenance at the Air Force Flight Standards Agency and an Adjunct Assistant Professor at EmbryRiddle Aeronautical University-Worldwide. He is a certified ATC specialist and Airfield Manager. He holds a Doctorate in Business Administration (DBA) in Leadership from Walden University and a Master of Aeronautical Science from Embry-Riddle.

Dr. Matthew Earnhardt is an Assistant Professor with Embry-Riddle Aeronautical University-Worldwide. He holds a PhD in Organizational Leadership with a Global Leadership Emphasis from Regent University. He has an undergraduate degree in Psychology, a MBA, and is working toward a Master of Aeronautical Science specializing in Human Factors in Aviation Systems, Aviation/Aerospace Safety Systems, and Aviation/Aerospace Education Technology.

Dr. Jim Marion is an Assistant Professor with Embry-Riddle Aeronautical University-Worldwide. He serves as the Chair of the MS in Engineering Management program and teaches in the MS in Project Management program. His experience includes multiple product launches in the US, Europe, and Asia, and significant experience with Japanese companies. Dr. Marion has a PhD in Organization and Management from Capella University, an MS in Engineering and a MSc. and a MBA in Strategic Planning.

Dr. Rose Opengart is an Assistant Professor with Embry-Riddle Aeronautical University-Worldwide. She holds a PhD in HROD -Human

Resources/Organizational Development, a post-doctoral certificate from AACSB in Marketing and Management, and professional certification, PHR, in Human Resources.

Dr. Aaron Glassman is an Assistant Professor of Management and Chair of the Department of Management and Technology at Embry-Riddle Aeronautical University-Worldwide. He holds a DM from the University of Maryland University College and a Master of Aeronautical Science from Embry-Riddle. 


\section{References}

AABI. (2014). Programs. Retrieved from http://www.aabi.aero/programs.html

Aguado, D., Arranz, V., Valera-Rubio, A., \& Marín-Torres, S. (2011). Evaluating a blended-learning program on developing teamwork competence. Psicothema, 23(3), 356.

Ahsan, K., Ho, M., \& Khan, S. (2013). Recruiting project managers: A comparative analysis of competencies and recruitment signals from job advertisements. Project Management Journal, 44(5), 36-54. doi:10.1002/pmj.21366

Appelbaum, S. H., \& Fewster, B. M. (2002). Global aviation human resource management: Contemporary recruitment and selection and diversity and equal opportunity practices. Equal Opportunities International, 21(7), 6680. doi:10.1108/02610150210787226

Ascher, J. (2013). Training transfer: A suggested course of action for local authorities to leverage performance. Performance Improvement, 52(5), 3643. doi:10.1002/pfi.21348

Breaugh, J. A., \& Starke, M. (2000). Research on employee recruitment: So many studies, so many remaining questions. Journal of management, 26(3), 405434. doi:10.1177/014920630002600303

Boyles, T. (2012). 21st century knowledge, skills, and abilities and entrepreneurial competencies: A model for undergraduate entrepreneurship education. Journal of Entrepreneurship Education, 15, 41.

Burke, R. J., \& Ng, E. (2006). The changing nature of work and organizations: Implications for human resource management. Human Resource Management Review, 16(2), 86-94. doi:10.1016/j.hrmr.2006.03.006

Carifio, J., \& Perla, R. J. (2007). Ten common misunderstandings, misconceptions, persistent myths and urban legends about Likert scales and Likert response formats and their antidotes. Journal of Social Sciences, 3(3), 106-116. doi:10.3844/jssp.2007.106.116

Carifio, J., \& Perla, R. (2008). Resolving the 50-year debate around using and misusing Likert scales. Medical education, 42(12), 1150-1152. doi: 10.1111/j.1365-2923.2008.03172.x

Carless, S. A. (2005). Person-job fit versus person-organization fit as predictors of organizational attraction and job acceptance intentions: A longitudinal 
study. Journal of Occupational and Organizational Psychology, 78(3), 411-429. doi:10.1348/096317905X25995

Chan, C. Y., Yen, C. H., Tsai, F. C. (2014). Job crafting and job engagement: The mediating role of person-job fit. International Journal of Hospitality Management, 37, 21-28. doi:/10.1016/j.ijhm.2013.10.006

Christensen, R. K. \& Wright, B. E. (2011). The effects of public service motivation on job choice decisions: Disentangling the contributions of person-organization fit and person-job fit. Journal of Public Administration Research, 21(4), 723-743, doi:10.1093/jopart/muq085

Clark, J. M. (2006). The face of collegiate aviation: Factors impacting selfselection of collegiate aviation programs. Collegiate Aviation Review, 24(1), 42-57.

de Winter, J. C., \& Dodou, D. (2010). Five-point Likert items: t test versus MannWhitney-Wilcoxon. Practical Assessment, Research \& Evaluation, 15(11), 1-12.

Earnhardt, M. P., Newcomer, J. M., Watkins, D. V., \& Marion, J. W. (2014). An inquiry into the aviation management education paradigm shift. International Journal of Aviation, Aeronautics, and Aerospace, 1(4). doi:10.15394/ijaaa.2014.1037

Earnhardt, M. P. (2014). Romans 12 motivational gifts in the military: An exploration of person-job fit, job performance, and job satisfaction. Journal of Biblical Integration in Business, 17(1), 59-72. Retrieved from http://www.cbfa.org/JBIB_vol17_inside_rev-final.pdf

Edwards, J. R. (1991). Person-job fit: A conceptual integration literature review and methodological critique. International Review of Industrial and Organizational Psychology, 6, 283-357.

Ehrhart, K. H. (2006). Job characteristic beliefs and personality as antecedents of subjective person-job fit. Journal of Business and Psychology, 21(2), 193226. doi:/10.1007/s10869-006-9025-6

FAA. (2010). Mission. Retrieved from http://www.faa.gov/about/mission/

Fanjoy, R. O., \& Gao, Y. (2007). Collegiate aviation in china: Opportunities and challenges. Journal of Aviation/Aerospace Education \& Research, 17(1). Retrieved from http://commons.erau.edu/jaaer/vol17/iss1/4

Ferguson, M. D., \& Johnson, J. A. (2007). Cost and perceived value in obtaining a bachelor's degree in aviation professional flight: Will collegiate aviation 
price themselves out of the market with technologically advanced aircraft? Journal of Aviation/Aerospace Education \& Research, 17(1).

Flynn, T. (2014). Do they have what it takes? A review of the literature on knowledge, competencies, and skills necessary for twenty-first-century public relations practitioners in Canada. Canadian Journal of Communication, 39(3), 361.

Fraser, K., \& Hvolby, H. (2010). Effective teamworking: Can functional flexibility act as an enhancing factor? Team Performance Management, 16(1/2), 74-94. doi:10.1108/13527591011028933

George, D., \& Mallery, P. (2003). SPSS for Windows step by step: A simple guide and reference. 11.0 update (4th ed.). Boston: Allyn \& Bacon.

Glassman, A. M., Newcomer, J. M., Earnhardt, M. P., Opengart, R. A., Watkins, D. V., \& Marion, J. W. (2015). Validating the knowledge, skills, and abilities composite measure: An aviation industry pilot study. International Journal of Aviation, Aeronautics, and Aerospace, 2(3). doi:10.15394/ijaaa.2015.1067

Guillory, J., \& Hancock, J. T. (2012). The effect of LinkedIn on deception in resumes. Cyberpsychology, Behavior \& Social Networking, 15(3), 135140. doi:10.1089/cyber.2011.0389

HR in the Federal Sector. (2006). Alexandria, VA: Society for Human Resource Management

Hambleton, A. J., Kalliath, T., \& Taylor, P. (2000). Criterion-related validity of a measure of person-job and person- organization fit. New Zealand Journal of Psychology, 29(2), 80-85.

Hinami, K., Whelan, C. T., Miller, J. A., Wolosin, R. J. \& Wetterneck. T. B. (2013). Person-job fit: An exploratory cross-sectional analysis of hospitalists. Journal of Hospital Medicine, 8(2), 96-101. doi:10.1002/jhm.1995

Johnson, J. P., Lenartowicz, T., \& Apud, S. (2006). Cross-cultural competence in international business: Toward a definition and a model. Journal of International Business Studies, 37, 525-543. doi:10.1057/palgrave.jibs. 840020

June, S., Kheng, Y. K., \& Mahmood, R. (2013). Determining the importance of competency and person-job fit for the job performance of service SMEs employees in Malaysia. Asian Social Science, 9(10), 114-123. doi:10.1002/jhm.1995 
Kraus, D.C. \& Gramopadhye, A.K. (2001). Effect of team training on aircraft maintenance technicians: computer-based training versus instructor-based training. International Journal of Industrial Ergonomics, 27(3), 141-157. doi:10.1016/S0169-8141(00)00044-5

Kreuter, F., Presser, S., \& Tourangeau, R. (2008). Social desirability bias In CATI, IVR, and web surveys. Public Opinion Quarterly, 72(5), 847-865. doi:10.1093/poq/nfn063

Kristof-Brown, A.L. (2000). Perceived applicant fit: distinguishing between recruiters' perceptions of person-job and person-organization fit.Personnel Psychology, 53(3), 643-71. doi:10.1111/j.17446570.2000.tb00217.x

Kristof-Brown, A. L., Zimmerman, R. D., \& Johnson, E. C. (2005).

Consequences of individuals' fit at work: A meta-analysis of person-job fit, person-organization, person-group, and person-supervisor-fit.

Personnel Psychology, 58, 281-342. doi:10.1111/j.1744-6570.2005.00672.x

Kuhn, T. S. (1996). The structure of scientific revolutions (3rd ed.) Chicago, IL: University of Chicago Press. doi:10.7208/chicago/9780226458106.001.0001

Lauver, K. J., \& Kristof-Brown, A. (2001). Distinguishing between employees' perceptions of person-job and person-organization fit. Journal of Vocational Behavior, 59(3), 454-470. doi:10.1006/jvbe.2001.1807

Lin, Y., Yu, C., \& Yi, C. (2014). The effects of positive affect, person-job fit, and well being on job performance. Social Behavior and Personality, 42(9), 1537-1547. doi:10.2224/sbp.2014.42.9.1537

Liu, D., Reynolds, C., Vincenzi, D., \& Doherty, S. (2013). Effect of pilot and air traffic control experiences and automation management strategies on unmanned aircraft systems mission task performance. Human Factors and Ergonomics in Manufacturing \& Service Industries, 23(5), 424-435. doi:10.1002/hfm.20330

Loffi, J. M., Bliss, T. J., \& Depperschmidt, C. L. (2013). Identifying knowledge demands and professional skill sets for employment within the aviation security environment: A qualitative inquiry of aviation security professionals. Journal of Transportation Security, 6(3), 235-256. doi:10.1007/s12198-013-0114-2 
Malakis, S. \& Kontogiannis, T. (2012). Refresher training for air traffic controllers: Is it adequate to meet the challenges of emergencies and abnormal situations? The International Journal of Aviation Psychology, 22(1), 59-77. doi:10.1080.10508414.2012.635127

Mathis, R.L., Jackson, J.J., \& Valentine, S.R. (2011) Human Resource Management. CT: Cengage Learning

Moy, J. W., \& Lam, K. F. (2004). Selection criteria and the impact of personality on getting hired. Personnel Review, 33(5), 521-535. doi:10.1108/00483480410550134

Neistadt, J. \& Murphy, T. J. (2009). Are we really saving resources with current hiring practices at local health departments? Journal of Environmental Health, 71(6), 12-4.

Newcomer, J. M., Marion Jr., J. W., \& Earnhardt, M. P. (2014). Aviation managers' perspective on the importance of education. International Journal of Aviation, Aeronautics, and Aerospace, 1(2). doi:10.15394/ijaaa.2014.1014

Norman, G. (2010). Likert scales, levels of measurement and the "laws" of statistics. Advances in health sciences education, 15(5), 625-632. doi:10.1007/s10459-010-9222-y

O'Neil, P. D. (2011), High reliability systems and the provision of a critical transportation service. Journal of Contingencies and Crisis Management, 19, 158-168. doi:10.1111/j.1468-5973.2011.00645.x

O'Neill, T. A., Goffin, R. D., \& Gellatly, I. R. (2012). The knowledge, skill, and ability requirements for teamwork: Revisiting the Teamwork- KSA test's validity. International Journal of Selection \& Assessment, 20(1), 36-52. doi:10.1111/j.1468-2389.2012.00578.x

OPM.gov. (n.d.). Classification and qualification: General schedule qualification standards. Retrieved from http://www.opm.gov/policy-dataoversight/classification-qualifications/general-schedule-qualificationstandards/2100/air-traffic-control-series-2152/

Parsons, F. (1909). Choosing a vocation. Boston, MA: Houghton-Mifflin.

Patino, A., Pitta, D., Quinones, R., (2012). Social media's emerging importance in market research. Journal of Consumer Marketing, 29(3), 233-237. doi:10.1108/07363761211221800 
Quilty, S. M. (2004). Airport management program and curriculum issues at 2and 4-year aviation colleges and universities. Collegiate Aviation Review, 22(1), 57-70.

Radigan, J. A. (2011). The impact of specialized accreditation on program quality: Aviation students' perspectives. Collegiate Aviation Review, 29(2), 58-77. Retrieved from http://www.imis100us1.com/UAA/UAAMain/Publications

Rajagani-Diwyaa, V. (2014). Relationship between mentoring, self-efficacy, person job-fit and school culture with work adjustment among new teachers. Asian Social Science, 10(16), 90-98. doi:10.5539/ass.v10n16p90

Roth, W., \& Mavin, T. J. (2015). Peer assessment of aviation performance: Inconsistent for good reasons. Cognitive Science, 39(2), 405-433. doi:10.1111/cogs.12152

Ruiz, J. R. (2007). Current trends in air traffic controller recruitment and training. Journal of Aviation/Aerospace Education \& Research, 16(2). Retrieved from http://commons.erau.edu/jaaer/vol16/iss2/4

Ruiz, L. E., Voges, J. K., \& Mortag, K. (2006). Perceptions of an aviation flight practicum: A follow-up study of graduates of an aviation flight practicum course. Journal of Aviation/Aerospace Education \& Research, 15(3). Retrieved from http://commons.erau.edu/jaaer/vol15/iss3/9

Sadasivan, S. \& Gramopadhye, A.K. (2009). Technology to support inspection in the general aviation industry: Specification and design. International Journal of Industrial Ergonomics, 39(4), 608-620. doi:10.1016/j.ergon.2008/09/002

Sax, L. J., Gilmartin, S. K., \& Bryant, A. N. (2003). Assessing response rates and nonresponse bias in web and paper surveys. Research in Higher Education, 44(4), 409-432. doi:10.1023/A:1024232915870

Sekiguchi, T. (2003). The role of person-organization fit and person-job fit in managers' hiring decisions: The effects of work status and occupational characteristics of job openings (Doctoral dissertation). Retrieved from ProQuest Digital Dissertations. (UMI No. 3102714).

Sekiguchi, T. \& Huber, V. L. (2011). The use of person-organization fit and person-job fit information in making selection decisions. Organizational Behavior and Human Decision Processes. 116(2), 203-216. doi:10/1016/j/obhdp.2011.04.001 
Shawn, M., Kim, M., \& Jitendra, M. (2014). Elderly workers in the workforce. Advances in Management, 7(3), 1-5.

Sweem, S., \& Stowe, M. (2012). Six C's of continuing care retirement communities (CCRC) leadership development. Academy of Strategic Management Journal, 11(1), 27.

Wooten, W. (1993). Using knowledge, skill and ability (KSA) data to identify career pathing opportunities: An application of job analysis to internal manpower planning. Public Personnel Management, 22(4), 551. doi:10.1177/009102609302200405

Worrells, D. S. (2010). Barriers to work-based learning in aviation management programs. Journal of Aviation/Aerospace Education \& Research, 19(3), 15. Retrieved from http://commons.erau.edu/jaaer/vol19/iss3/2

Wu, L., Wei, L., Zhang, Y., \& Han, T. (2011). Employee experienced HPWPs and job performance: Roles of person-job fit and intrinsic motivation. Frontiers of Business Research in China, 5(3), 344-363. doi:10.1007/s11782-011-0134-3 